\title{
EFFECT OF SOME FRESH WATER ALGAE ON NUTRIENT COMPOSITION OF SAFFLOWER (CARTHAMUS TINCTORIUS L.)
}

\author{
D. N. Gholap ${ }^{1}$, B. K. Auti ${ }^{2}$ and A. S. Wabale ${ }^{3 *}$ \\ ${ }^{1}$ Arts, Commerce and Science College, Satral, Tah. Rahuri, Dist. Ahmednagar (M.S.) \\ ${ }^{2}$ Radhabai Kale Mahila Mahavidhyalaya, Ahmednagar \\ *3Padmashri Vikhe Patil College of Arts, Science and Commerce, Pravaranagar- 413 \\ 713 \\ Email- deepakgholap1972@gmail.com
}

Communicated: 21.02 .21

Revision : 16.03.21 \& 19.04.2021

Accepted: 8.05 .2021

Published: 30.05 .2021

\begin{abstract}
:
Current agriculture is depending upon gradually more use of chemical fertilizers. Such chemical fertilizers can cause unfavourable effect on soil fertility. Use of bio-fertilizers in agriculture will help in harmless effect on the soil health and also the quality of crop products. A good number of the algae are associated with the plant roots which can improve the crop yield and soil richness. In present work fresh water algae are collected from rivers and canals of Rahata tahsil. This collected fresh water algae are shade dried and a fine powder was made. This powder was used for preparation of aqueous and Indian khillar cow urine extracts of various concentrations. A leafy vegetable, Safflower (Carthamus tinctorius L.) was used as a tested plant. Seeds of safflower were soaked with this algal extract concentration. Study was conducted during rabbi season 2020 by designing Randomized Block Design (RBD) method. The 20\% algal extract with cow urine tested for its potential as a liquid biofertilizer on Safflower showed significant positive results. Fresh leaves after 60 DAS treatment showed maximum increase in nutrient composition.
\end{abstract}

Keywords: Biofertilizer, Algae, Safflower, RBD, Nutrient.

\section{INTRODUCTION:}

Recent agriculture is depending upon more and more use of chemical fertilizers. Such chemical fertilizers can cause adverse effect on soil fertility. Use of bio-fertilizers in agriculture will help in harmless effect on the soil health and also the quality of crop products. Most of the algae are associated with the plant roots which can improve the crop productivity and soil fertility.

Safflower (Carthamus tinctorius L.) is an important oilseed crop rich in polyunsaturated fatty acids which helps in reducing cholesterol level in blood. Flowers of safflower are used as a natural source of edible colours and exhibit several medicinal properties. Tender leaves and shoots of safflower are used as potherb and salad in and around the area of production in India and some neighboring countries (Nimbkar.N. 2002). Safflower leaves are good source of fiber, minerals, vitamins and antioxidants (Vrijendra Singh et al 2017; Suneel Kumar et.al 2016).

In the present investigation, an attempt was made to prepare fresh water algal liquid extract as a biofertilizer. Fresh water algae collected from Rahata tahsil of Ahmednagar district were tested for their efficacy as liquid biofertilizer on Safflower (Carthamus tinctorius L.). After treatment safflower fresh leaves were 
I J R B A T, Issue (IX), Vol. II, May 2021: 247-251

A Double-Blind Peer Reviewed \& Refereed Journal
OPEN $\bigcirc$ ACCES

e-ISSN 2347 - 517X

Original Article analyzed for nutrient composition which shows maximum increase in nutrient content.

\section{MATERIALS AND METHODS:}

\section{Collection of Fresh Water Algae}

Fresh water algae were collected from the study area i.e. from canals and rivers of Rahata tahsil of Ahmednagar district. Algae was handpicked and washed with running tap water to remove the unwanted impurities and soils particles. Further, the collected samples from different locations were kept in separate plastic bags of suitable sizes and brought to the laboratories.

\section{Preparation of Algal Powder}

Washed algal samples from river and canal were shade dried seperatly in the laboratory. Completely dried material was crush to obtain fine powder. (Aher and Wabale, 2019). Algal powder was stored in airtight plastic containers for further use i.e. for preparation of extract in order to study their potential as a liquid biofertilizer.

\section{Preparation of Algal extracts}

To study the effect of algae on tested plant safflower, extracts were prepared by using Indian breed Khillar cattle urine and DW. 10 gm of algal powder extract was prepared with $100 \mathrm{ml}$ of cow urine and DW separately by boiling it to a final volume of $10 \mathrm{ml}$. Six treatments, T1-Control (D.W.), T2-Control Cow Urine 20\%, T3-Aqueous algal extract (Pravara River) $20 \%$, T4 - Cow Urine + Algal extract (Pravara River) 20\%, T5 - Aqueous algal extract (Pravara Canal) 20\%, T6- Cow Urine + Algal extract (Pravara Canal )20\% were prepared separately in glass bottles. It is further used for spraying on experimental plot.

\section{Testing the effect of liquid biofertilizer on safflower}

Further safflower seeds were soaked in the above concentrations for 12 hours. These soaked seeds were sown in the experimental plot with six treatments and four replications and liquid spray of six treatments were given to tested plants.

\section{Field experiment:}

Field experiment was conducted at Arts, Commerce and Science college Satral. The experiment was laid out in Factorial Randomized Block Design [RBD] during Rabbi season with six treatments on Safflower and replicated four times. Foliar spray was given after 15 days of interval.

\section{Element composition:}

For the estimation of minerals $1 \mathrm{gm}$ oven dried sample powder of leaves of various treatments was acid digested (Toth et al.,1948). This acid digested extract was further used for the estimation of Potassium, Phosphorous by using Flame photometer and Magnesium, Ferrous, Zink and Iron by using Atomic Absorption Spectrophotometer (R.B.Somwanshi et al) model Chemito AA203 at Krishi Vidyan Kendra Babhaleshwar, Tal. Rahata.

\section{RESULT AND DISCUSSION:}

During present investigation element composition was done with the help of atomic absorption spectrophotometer (AAS). In 20\% concentration of fresh water canal algal extract with cow urine showed higher increase in element composition like Potassium (K), Phosphorous (P), Magnesium (Mg), Iron (Fe), Zinc $(\mathrm{Zn})$. As control and other treatment $\mathrm{T} 1$, T2, T3, T4, T5 the T6 treatment (the extract with the cow urine) showed good results.

\section{SUMMARY AND CONCLUSION:}

Present study showed significant positive effect of $20 \%$ fresh water algal extract with Indian cattle urine on nutrient content of Carthamus 
tinctorius. Maximum nutrient content was obtained with T6 treatment than rest of the treatments.

1. Fresh water algae are studied as good alternative for synthetic chemical fertilizer and ultimately recommended with proper doses as liquid fertilizer to enhance Safflower as highly nutritious leafy vegetables.

2. Nutrient content of safflower leaves was higher in $20 \%$ concentration it indicates that safflower leaves are rich source of minerals, which if included in regular diet, can enhance the mineral content.

\section{ACKNOWLEDGEMENT:}

The authors are very grateful to the research center of Padmashri VikhePatil College of Arts, Science and Commerce, Pravaranagar for the facilities required to carry out the research work.

\section{REFERENCES:}

A.A. Aher and A.S. Wabale (2016), Effect of liquid algal extract on seed germination and seedling growth in Okra (Abelmoschus esculenntus L.). International journal of recent trends in scienceand technology, 4143, special issue 2016.

Nimbkar.N,2002. Safflower rediscovered. Times Agricultural Journal, 2: 32-36

R.B. Somawanshi, A.D. Kadlag, A.N. Deshpande, B.D. Tamboli, P.P. Kadu and B.D. Bhakare. Laboratory methods for analysis of soils, irrigation water and plants, University publication, Department of soil science and agricultural chemistry, M.P.K.V. Rahuri.

Vrijendra Singh, R.R. Jadhav, G.E. Atre, J.V. Kale, P.T. Karande, K.D.Kanbargi, N. Nimbkar and A.K. Rajvanshi, 2017. Safflower (Carthamus tinctorius L)-an underutilized leafy vegetable. Current Science.113 (5):857-858.September 2017.

Suneel Kumar, Aparna Kuna, P Padmavathi, CH V Durga Rani, Supta Sarkar. Nutrient composition of selected cultivars of safflower (Carthamus tinctorius L.) leaves during different crop growth stages to water stress. J. Oilseeds., 33(4): 216-220, December, 2016.

1: Effect of algal liquid biofertilizer on nutrient composition of safflower leaves.

\begin{tabular}{|c|c|c|c|c|c|}
\hline Treatment & Mg (ppm) & Fe (ppm) & Zn (ppm) & $\begin{array}{c}\mathbf{K} \\
\text { (\%) }\end{array}$ & $\begin{array}{c}\mathbf{P} \\
\text { (\%) }\end{array}$ \\
\hline $\mathrm{T} 1$ & 0.62 & 582.26 & 54.05 & 1.83 & 0.10 \\
\hline $\mathrm{T} 2$ & 0.63 & 609.18 & 56.2 & 2.02 & 0.11 \\
\hline $\mathrm{T} 3$ & 0.65 & 615.05 & 61.33 & 2.11 & 0.13 \\
\hline $\mathrm{T} 4$ & 0.74 & 652.62 & 65.81 & 2.19 & 0.12 \\
\hline $\mathrm{T} 5$ & 0.7 & 638.22 & 59.43 & 2.06 & 0.11 \\
\hline $\mathrm{T} 6$ & 0.78 & 705.64 & 72.5 & 2.28 & 0.14 \\
\hline
\end{tabular}



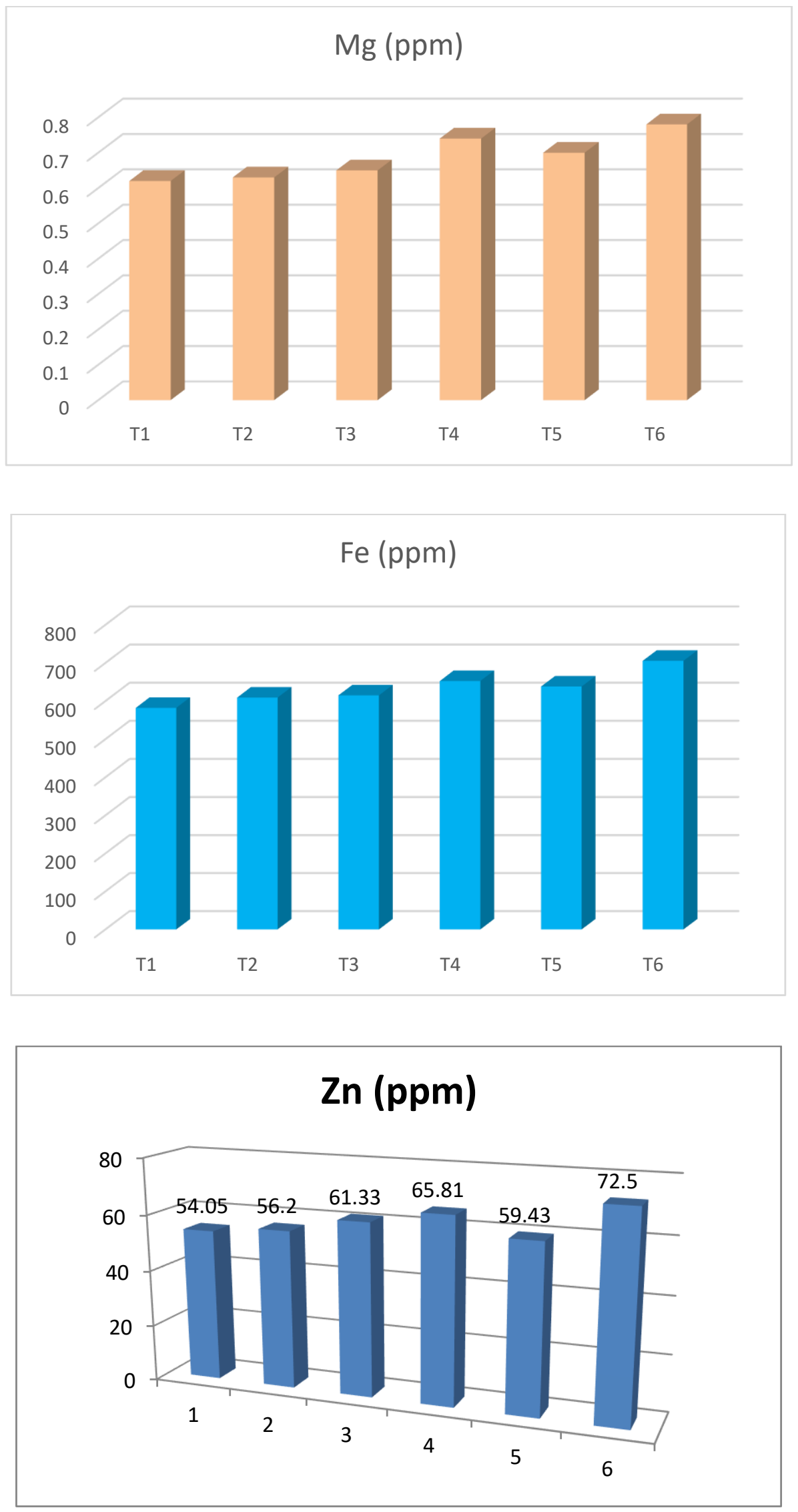

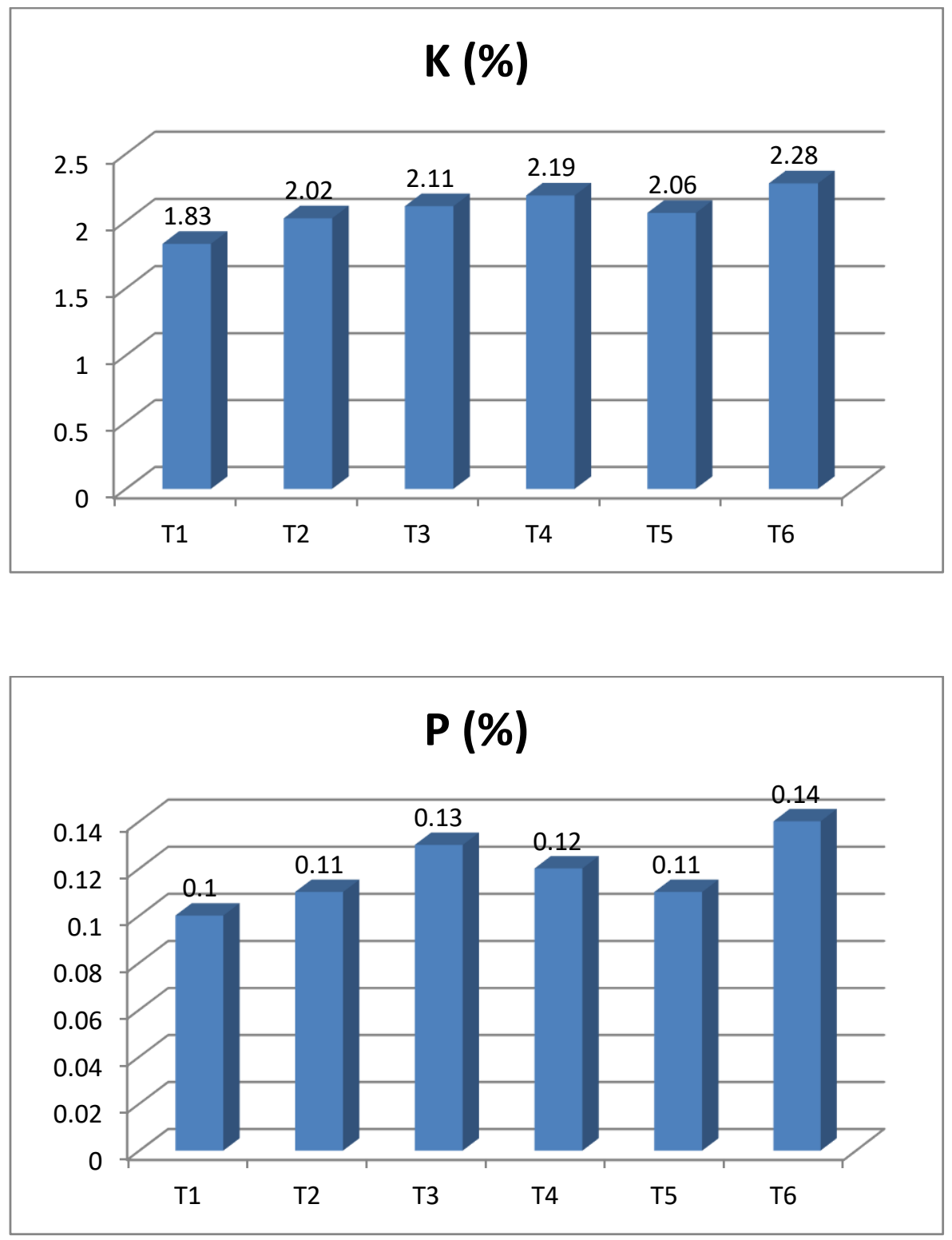